\title{
Dairy farmers' use and non-use values in animal welfare: Determining the empirical content and structure with anchored best-worst scaling
}

\author{
H. Hansson ${ }^{1,2}$ and C. J. Lagerkvist ${ }^{1}$ \\ Department of Economics, Swedish University of Agricultural Sciences, PO Box 7013, SE-75007 Uppsala, Sweden
}

\begin{abstract}
In this study, we sought to identify empirically the types of use and non-use values that motivate dairy farmers in their work relating to animal welfare of dairy cows. We also sought to identify how they prioritize between these use and non-use values. Use values are derived from productivity considerations; non-use values are derived from the wellbeing of the animals, independent of the present or future use the farmer may make of the animal. In particular, we examined the empirical content and structure of the economic value dairy farmers associate with animal welfare of dairy cows. Based on a best-worst scaling approach and data from 123 Swedish dairy farmers, we suggest that the economic value those farmers associate with animal welfare of dairy cows covers aspects of both use and non-use type, with non-use values appearing more important. Using principal component factor analysis, we were able to check unidimensionality of the economic value construct. These findings are useful for understanding why dairy farmers may be interested in considering dairy cow welfare. Such understanding is essential for improving agricultural policy and advice aimed at encouraging dairy farmers to improve animal welfare; communicating to consumers the values under which dairy products are produced; and providing a basis for more realistic assumptions when developing economic models about dairy farmers' behavior.
\end{abstract}

Key words: animal welfare of dairy cow, best-worst scaling, economic value in animal welfare, non-use value, use value

\footnotetext{
Received April 27, 2015.

Accepted September 22, 2015.

${ }^{1}$ Both authors contributed equally to this study.

${ }^{2}$ Corresponding author: Helena.Hansson@slu.se
}

\section{INTRODUCTION}

The living conditions of animals in farm production are becoming an increasingly important topic of public concern. Lusk et al. (2007) report that a majority (62\%) of representatives of US households think that the wellbeing of farm animals should be considered even in the presence of suffering among humans. In the European Union (EU), evidence presented within the Welfare Quality project shows that consumers in the EU are concerned about the wellbeing of farm animals (Ingenbleek and Immink, 2011). The recognition of animals as sentient beings that can suffer unless handled properly has resulted in farm animal welfare (FAW) regulations of both a public and private nature in the EU region.

In discussions about how to regulate FAW, including FAW in dairy production, a thorough understanding of farmers and their decision-making with respect to FAW should receive special attention. Farmers' welfare-related choices, such as complying with current FAW regulations or providing better FAW standards than required by regulations, will have a direct effect on animal wellbeing. From an economic perspective, McInerney (2004) noted that humans will care about animal welfare as long as their own utility is influenced by the conditions under which animals live. Furthermore, because farmers need to provide a certain FAW standard to satisfy FAW regulations, they encounter a constrained optimization problem where these regulations stipulate a lower limit of their FAW standards. Provision of FAW standards above FAW regulations can be expected to the extent that the farmers believe that there are economic benefits from so doing and that these benefits are not offset by the costs associated with FAW.

In particular, McInerney (2004) noted that farmers might derive 2 general types of economic value from working with their livestock: use and non-use values. Use values refer to economic values derived from productivity considerations; that is, the type of value that 
can be derived from any kind of production factor. However, and as noted by McInerney (2004), farmers may provide FAW beyond what would be justified from productivity concerns. This may be because they experience economic value associated with knowing that their animals are treated well. It may also be because the farmers feel uncomfortable with pushing the animals toward their biological maximal productivity, even if that would be advantageous in terms of maximizing profit. Non-use values have come to be defined as "the value that producers derive from economic goods related to the wellbeing of livestock independent of any use, present or future, that the producer might make of the animals" Lagerkvist et al. (2011, p. 486). Consequently, the presence and accounting of non-use values in FAW are relevant in explaining why farmers provide FAW beyond the statutory requirements and beyond what would be justified if the animals were only viewed as production factors. Furthermore, non-use values may explain why farmers allow animals to produce at economically nonoptimal levels.

Lagerkvist et al. (2011) developed the notation of non-use values by identifying these as consisting of 5 theoretically separate types: pure non-use values, existence values, bequest values, option values, and paternalistic altruism. In the terminology of Lagerkvist et al. (2011), pure non-use values refer to economic values derived from provision of FAW beyond what would be defensible when considering its associated economic return. Existence values refer to economic values derived from treating the animals according to the absolute rights they are perceived to have, compliance with ethical codes among farmers, fulfillment of self-perception, and avoidance of discomfort associated with not treating animals well. Bequest values refer to economic values associated with maintaining and increasing the legitimacy of production involving animals. These values also refer to the economic value associated with preserving the possibilities to sustain animal production for future generations. Option values comprise economic values obtained from providing better food choices for consumers. Therefore, these are values derived from knowing that consumers can choose food products that are produced under animal-friendly production conditions. Paternalistic altruism refers to economic values derived from the establishment of lasting consumer-to-business relationships, from knowing that consumers are eating high-quality food products, and from gaining recognition from the industry and the food supply chain.

The framework related to use and non-use values in FAW thus recognizes why farmers may work with FAW, are prepared to comply with FAW regulations, and even provide FAW beyond the regulated requirements. Therefore, it is appealing to use the framework for describing farmers' FAW-related behaviors from a conceptual point of view. However, actual empirical existence of various use and non-use values in farmers' understandings of the economic value associated with FAW is lacking, and how farmers prioritize between these values is currently not well understood.

Previous literature has empirically investigated livestock farmers' FAW-related behaviors, including how farmers define FAW. For instance, Te Velde et al. (2002) found that farmers in the Netherlands believed their FAW to be good. Dockès and Kling-Eveillard (2006) found that farmers view FAW as being conditioned on that the animals need to produce. They also found that some viewed FAW as being about feeding and monitoring animal health, whereas others believe it was about the animals' psychological and behavioral needs. Furthermore, farmers participating in conventional or organic quality control schemes have been found to differ in their views on FAW (Hubbard et al., 2006, 2007). Those authors found that farmers participating in conventional quality control schemes viewed FAW as being related to the economic performance of the farm. They also found that those farmers participating in organic quality control schemes viewed FAW as being related to moral and ethical considerations. Kling-Eveillard et al. (2007) and van Huik and Bock (2007) have reported similar results. Previous studies have reported differences in the human-animal relationship depending on the species kept and the purpose of keeping the animal (Bock et al., 2007), which may affect farmers' views on FAW. Additionally, several studies have examined farmers' attitudes to FAW (e.g., Kauppinen et al., 2010, 2012; Kielland et al., 2010). Furthermore, based on in-depth interviews with 50 Swedish dairy farmers, Hansson and Lagerkvist (2015) examined the mental representation of FAW and deduced that both use and non-use values act as motivational factors in dairy farmers' decision-making and goal attainment with respect to FAW.

Notwithstanding the contribution made by previous literature, the empirical content, structure, and prioritization of the economic value associated with FAW have not yet been identified. Such information can be used for developing successful private and public FAW policy aimed at farmers, by taking determinants of farmers' behaviors into consideration. Understanding which type of FAW motivation drives behavioral action is relevant, because such motivation can be expected to influence farmers' cognition and productivity and is relevant as input to form their work motivation. Such information can also be useful for consumers interested 
in the origins of their food. Moreover, it could be important in the development of economic models of farmers' behaviors, by revealing interdependencies among use and non-use values.

In this study, we sought to identify the empirical content and structure of the domain of use and non-use values that motivate dairy farmers in their work related to the animal welfare of dairy cows (AWC). We also examined how they prioritize between these use and non-use values.

\section{MATERIALS AND METHODS}

\section{Conceptual Issues Related to the Measurement of Use and Non-Use Values}

A behavioral perspective was adopted in measuring the content and structure of farmers' use and non-use values. From this perspective, farmers' perceptions of, and preferences for, use and non-use values can be expected to determine their provision of FAW (Lagerkvist et al., 2011; Hansson and Lagerkvist, 2014). The type of FAW actions provided by a farmer can then be assumed to depend on a complex set of motivational variables. Critical aspects include goal directness; the extent to which farmers perceive their own needs and desires and those of others, including their animals; the extent of free will; and the sustainability of farmers' actions in relation to animal wellbeing. From a psychological perspective, it is well documented that perceptions of positive and negative phenomena direct people's motivated behavior (Carver and White, 1994), which explains how motivation as a stimulus leads to a behavioral response in a continual loop (Depue and Collins, 1999). Furthermore, because motivation exists on a continuum from rewarding (positive) to punishing (negative), farmers' behavior in relation to the provision of FAW can be expected to depend on how a certain action is perceived from a motivational perspective. As motivation drives behavioral action, it is reasonable to posit that the economic value associated with FAW is a theoretical construct (i.e., a theoretical concept) and that the various use and non-use values (as motivational drivers) can be taken as its attributes. It can also be posited that an order of these values exists that reflects their relative importance (i.e., priority). Thus, the theoretical construct can be measured by relative mapping of these attributes onto the motivational continuum. This approach to measuring the value farmers perceive in FAW has not been proposed previously.

A fundamental question in measurement of a theoretical construct is the causality between the construct and its measurement items (in the present case, the attributes). This is because this causality should drive the decision on which analytical method to use. Using the decision criterion for the type of measurement model developed by Jarvis et al. (2003), we suggest that there is a formative relationship between the economic value construct and its attributes. In particular, the motivational attributes are considered to define and give meaning to the construct. The attributes come together and form the construct, which would not exist without these attributes.

\section{Study Sample and Data Collection Procedures}

We collected the data for this study from November 2013 through January 2014. We recruited respondents by sending introductory letters to a random sample of 500 Swedish farmers specializing in dairy production. With assistance from Statistics Sweden (Örebro, Sweden), this sample was drawn from a register containing information about all farms in Sweden and their type of specialization. In the introductory letter, we briefly explained the study and asked farmers if they would consider participating by completing an internet-based questionnaire. We carried out data collection in collaboration with a market research company. Shortly after arrival of the introductory letter, the company contacted the farmers by phone to ask if they wanted to participate. Each farmer was called up to 5 times, and those not answering after 5 calls were not contacted again. For those who agreed to participate, the company sent a link for the questionnaire to each farmer by e-mail. Farmers who had not completed the questionnaire within 1 to 2 wk after agreeing to do so were reminded by a new phone call. The questionnaire is part of a larger research project and included 16 sets of questions, several of which were presented as scales with sub-questions. The estimated time required to complete the questionnaire was 30 to $40 \mathrm{~min}$. Respondents completing the questionnaire were sent a gift voucher worth 300 Swedish Krona (approximately US\$36) as a token of our appreciation of their time and effort. During the data collection process, 50 farmers declared that they were no longer part of the target group because they had quit dairy production, which left an effective sample of 450 farmers. Among these, 80 farmers could not be reached by phone on 5 attempts, 25 farmers were excluded because the records contained an incorrect phone number, 113 did not want to participate, and 232 agreed to answer the questionnaire. In total, 123 questionnaires were completed. This gave an effective response rate of $27.3 \%$. 


\section{Operationalization of Use and Non-Use Values}

We devised the attributes used to examine the content and structure of dairy farmers' economic value construct associated with AWC (see Table 1) by operationalizing its use and non-use value parts. In particular, we related motivational attributes covering use values to motivation to work with AWC for reasons concerning (1) maximal production, (2) maximal profitability, (3) the possibility to continue the business, (4) having time available for other things, (5) own work environment, (6) adjustments of production to current producer prices, (7) complying with animal welfare legislation, and (8) making a living from the business. Thus, motivational attributes covering use values included motivating aspects related to applying AWC to maintain productivity and profitability and to achieve business goals completely unrelated to AWC. Furthermore, we devised motivational attributes covering non-use values based on the 5 theoretical parts of the construct: pure non-use values, existence values, bequest values, option values, and paternalistic altruism (Lagerkvist et al., 2011). Using findings published in an interview study by Hansson and Lagerkvist (2015), we checked motivational attributes to cover aspects of economic value associated with AWC found in that study, to ensure that all use and non-use values found there were also covered in the present study. In particular, based on the study by Hansson and Lagerkvist (2015), we added motivational attributes related to the farmer's own work environment and to ensuring that the business makes a sufficient profit, so that the way in which the dairy cows are kept can be further improved (see Table 1). In total, 27 individual motivational attributes were devised.

\section{Anchored Best-Worst Scaling}

We used the best-worst scaling (BWS) approach (Finn and Louviere, 1992) to assess the empirical content, structure, and prioritization of the economic value construct in AWC. This approach is based on a wellfounded behavioral model of human decision-making (random utility theory; Thurstone, 1927; McFadden, 1974). The approach has not been used previously in evaluating how farmers prioritize between use and nonuse values in AWC (or FAW). In BWS, respondents were presented with repeated choice sets, generated by the experimental design, of objects belonging to the underlying set of motivational attributes (Table 1). These were taken to span the feature under study. The standard BWS results in relative mapping of each attribute on a common interval scale, which then permits inter-object comparison such as levels of importance in relation to one of the attributes within the feature set, so as to avoid the "dummy variable trap" (Lusk and Briggeman, 2009). Figure 1 illustrates the implementation of the BWS format in this study.

In the set of 5 attributes in Figure 1, the respondents indicated which they considered to be the most motivating attribute and the least motivating attribute. Using 5 objects $(J=5)$ in each choice set results in information about $\mathrm{J}(\mathrm{J}-1)-1=19$ paired comparisons. In each set of best-worst evaluations, the respondent is assumed to choose a pair of attributes that exhibits the largest motivational difference on the underlying unidimensional motivational gradient.

We used a heterogeneous design (Sándor and Wedel, 2005), rather than a blocked design, to govern the sequence and attributes of choice set shown to respondents. This design increases statistical efficiency by providing more variation across respondents and reducing problems of scale effects (these can be variations in preferences due to the block of the design from which data were generated). The heterogeneous design meant that respondents were randomly assigned one individual version of the full design. The design provided a balanced approach, with equal occurrence of each attribute. Each respondent was faced with 17 choice tasks, each containing 5 attributes.

The BWS approach has well-documented advantages over other available ranking and rating methods, such as providing better discrimination and being free from scale use bias. However, it also has the disadvantage of being relative in the sense that there is no rational zero for the common interval scale. Hence, the concept of "best" or "worst" is only comparable within a respondent and not across respondents (Lagerkvist et al. 2012). This means that the relative (standard) BWS approach would be inadequate in providing inputs to policy design.

To overcome these methodological shortcomings of the standard BWS approach, we adopted an anchored dual-response BWS format. This is in line with suggestions within business marketing research (Sawtooth Software, 2009). It is also in line with research showing that the anchoring format reduces heterogeneity and improves predictions of individual choices (Lagerkvist et al., 2012; Lagerkvist, 2013).

Figure 1 illustrates the implementation of the anchored BWS format in this study. In each choice set, after selecting a best-worst combination, we asked respondents to choose between the available attributes and an elaborated dual-response alternative. In the dual response, the alternative "some are important, some are not" served as a utility anchor that provided a zero level of utility. When selected, the alternative "all 5 are important" provided information to the estima- 


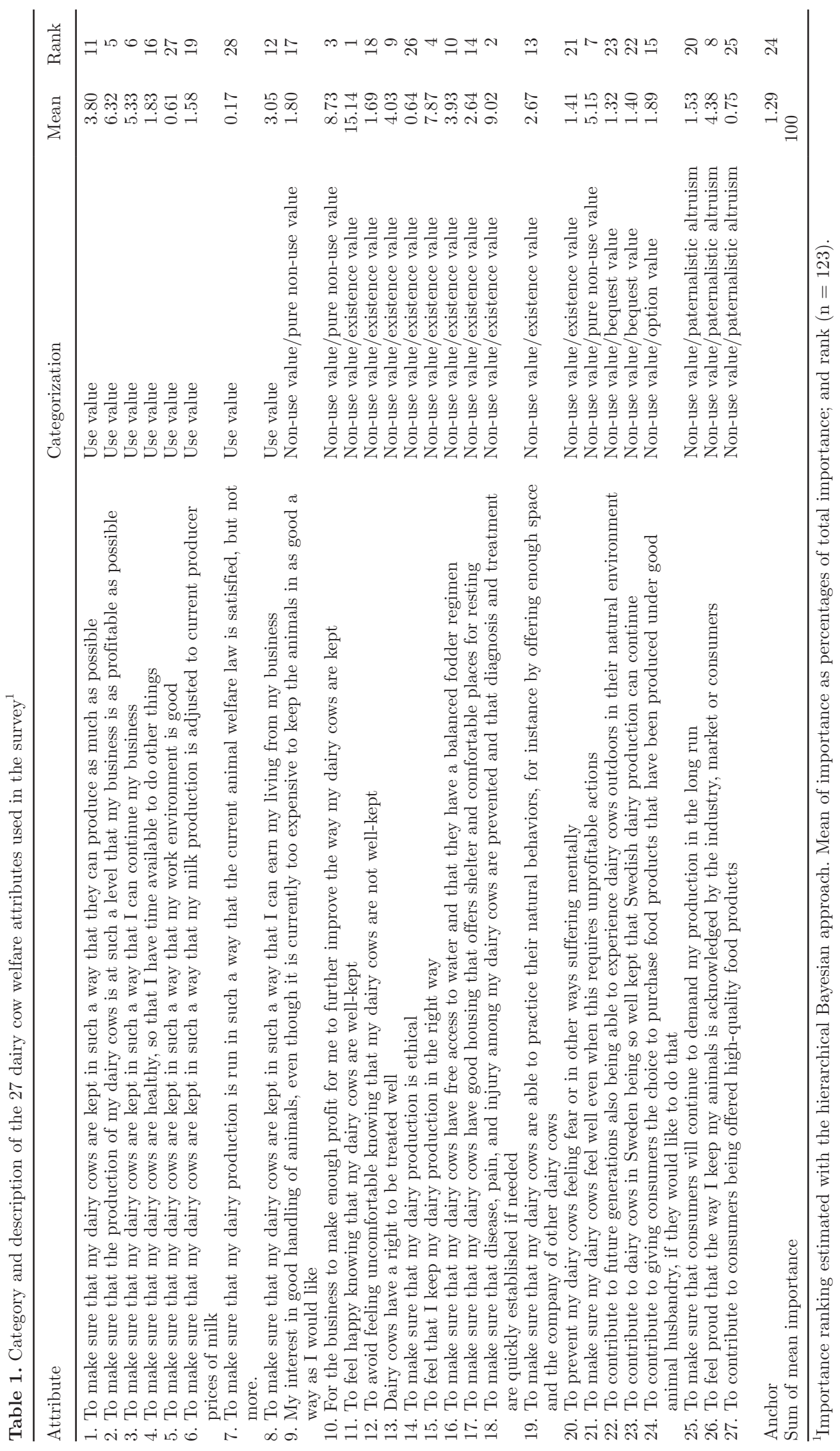


Please use the following table to indicate the importance you give to these five livestock-related features in relation to your dairy operation: which one motivates you the most and which one motivates you the least?

\begin{tabular}{|c|c|c|}
\hline $\begin{array}{l}\text { The most } \\
\text { motivating }\end{array}$ & Feature & $\begin{array}{l}\text { The least } \\
\text { motivating }\end{array}$ \\
\hline & $\begin{array}{l}\text { To make sure that my dairy cows are kept in such a way that I can } \\
\text { continue my business }\end{array}$ & \\
\hline & $\begin{array}{l}\text { To make sure that my dairy production is run in such a way that the } \\
\text { current animal welfare law is satisfied, but not more }\end{array}$ & \\
\hline & $\begin{array}{l}\text { My interest in good handling of animals, even though it is currently } \\
\text { too expensive to keep the animals in as good a way as I would like }\end{array}$ & \\
\hline & $\begin{array}{l}\text { To avoid feeling uncomfortable knowing that my dairy cows are not } \\
\text { well-kept }\end{array}$ & \\
\hline & $\begin{array}{l}\text { To prevent my dairy cows feeling fear or in other ways suffering } \\
\text { mentally }\end{array}$ & \\
\hline \multicolumn{3}{|c|}{ Considering just these five features... } \\
\hline o & None of these five is important & \\
\hline o & Some are important, some are not & \\
\hline o & All five are important & \\
\hline
\end{tabular}

Figure 1. Example of an anchored best-worst choice set used in the farmer survey.

tion that all 5 attributes should have a higher utility than the anchor. Similarly, the alternative "none of these 5 are important to me" indicated that each of the 5 motivational attributes shown had a utility lower than the anchor. The presence of the utility anchor then allows for an absolute ranking of attributes across respondents, and the anchor defines the zero level on the common interval scale (Lagerkvist et al., 2012). The coding of responses of the anchored BWS choices was based on the complete coding approach outlined by Lattery (2011).

There are several ways to analyze best-worst models (Marley and Louviere, 2005). Following Finn and Louviere (1992), the process outlined in relation to Figure 1 can be modeled based on the probability that an individual chooses the pair of attributes " $x$ most motivational, $y$ least motivational" from a set $\mathrm{Y}$ of $\mathrm{J}$ implicit paired choices that maximizes the distance between $x$ and $y$ on the underlying motivational gradient compared with all other possible paired differences in the set $\mathrm{Y}$, under random errors.

Because the exact locations assigned to each motivational attribute are unknown, it is only possible to specify a probability that a respondent will select a best-worst pair of attributes. Formally, let $\mathrm{T}$ denote the full set of available motivational attributes, meaning that there are $\mathrm{T}(\mathrm{T}-1)$ best-worst combinations, and let $\mathrm{D}(\mathrm{T})$ denote the set of choice tasks fixed by the study design (i.e., subsets of motivational factors that occur in the study). For any subset $Y \in D(T)$ with $J$ alternatives plus the anchoring question, let $\mathrm{B}_{\mathrm{Y}}(x)$ denote the probability that motivational attribute $x$ is chosen 
as best in $\mathrm{Y}, \mathrm{W}_{\mathrm{Y}}(y)$ the probability that motivational attribute $\mathrm{y}$ is chosen as worst in $\mathrm{Y}$, and $\mathrm{BW}_{\mathrm{Y}}(x, y)$ the probability that $x$ is chosen as best in $\mathrm{Y}$ and $y \neq x$ is chosen as worst in Y.

Within the sampled population of dairy farmers in Sweden, heterogeneity was assumed to exist for the position of each motivational attribute. To obtain individual estimates on the location of motivational attributes, we let $\mathrm{u}_{\mathrm{k}}(i)$ represent the position of a given alternative $i$ on the underlying motivational gradient for individual $k$. This weight is specified as a randomeffects model:

$$
\left\{u_{k}(i)\right\}_{i=1}^{T}=\bar{u}+\mu_{k i},
$$

where $\overline{\boldsymbol{u}}$ is a vector of means of each $u(i)$ within the population and $\mu_{k}$ is a T-dimensional multivariate normally distributed disturbance term related to the deviation of each individual's location of each attribute from the sample mean, where $\mu \sim \operatorname{MVN}\left(0, \mathbf{V}_{u}\right)$, and $\mathbf{V}_{u}$ denotes the covariance matrix of that distribution.

In a decision-making process where $x$ is chosen first and then $y$ is selected from among the remaining attributes, it follows from Finn and Louviere (1992), Marley and Louviere (2005), Lusk and Briggeman (2009), Cross et al. (2012), and Erdem et al. (2012) that the mixed logit choice model for a set, $\mathrm{Y} \in \mathrm{D}(\mathrm{T})$, of bestworst (BW) choice probabilities onto the $(0,1)$ interval becomes

$$
\begin{aligned}
B W_{k Y}(x, y) & =\frac{e^{u(x-u(y)}}{\sum_{l}^{J} \sum_{m}^{J} e^{u(l)-u(m)}-J+1} \\
& =P\left[\left(\delta_{x y}+\eta_{x, y}\right)>\operatorname{Max}\left(\delta_{l m}+\eta_{l m}\right)\right],
\end{aligned}
$$

for all $l m$ in $\mathrm{Y}(2)$, where the +1 scalar in the numerator of Eq. [2] introduces the anchoring question. The given rational zero-scale alternative "some are important, some are not" thereby provides the absolute level against which the location of the motivational attributes in $\mathrm{T}$ is identified. The term $\delta_{x y}+\eta_{x, y}$ represents the difference between alternatives $x$ and $y$ on the motivational gradient, plus a random error term, whereas $\operatorname{Max}\left(\delta_{l m}+\eta_{l m}\right)$ is the largest of all other paired differences within the choice set.

The model in Eq. [2] with individual locations of motivational attributes expressed as part-worth utilities can be estimated by a random parameter model (RPL) or calculated using hierarchical Bayesian logit procedures (HB; Train, 2009). Previous comparisons between RPL and HB models (e.g., Huber and Train, 2001) suggest that both models yield similar results.
The HB approach to Eq. [1] and [2] is based on Rossi and Allenby (1993) and Allenby (1997), allowing inferences about a specific respondent's part-worths as a function of that respondent's choice data and the distribution of the locations across the sampled population. The bottom of the hierarchy is specified by Eq. [2], which corresponds to the observed choice data generation process. The weights each respondent assigns to the motivational attribute are linked in Eq. [1] by a common distribution. The parameters $\overline{\boldsymbol{u}}$ and $\mathbf{V}_{u}$ in Eq. [1] are therefore at the top of the hierarchy. The individual part-worths then vary from person to person under the common parameter $\mathbf{V}_{u}$. Following the Bayes rule, the vector of $\boldsymbol{u}_{k}(i)$ for each individual respondent given all available data $P\left(\boldsymbol{u}_{k} \mid D a t a\right)$ is obtained from the joint probability of all model parameters in the data (Allenby and Rossi, 2003) as

$$
\begin{aligned}
P\left(\left\{u_{k}\right\}, \overline{\boldsymbol{u}}, \mathbf{V}_{u} \mid \text { Data }\right)= & {\left[\Pi_{k} P\left(\text { Data }_{k} \mid \boldsymbol{u}_{k}\right) \times P\left(\boldsymbol{u}_{k} \mid \overline{\boldsymbol{u}}, \mathbf{V}_{u}\right)\right] } \\
& \times P\left(\overline{\boldsymbol{u}}, \mathbf{V}_{u}\right) / P\left(\{\text { Data }\}_{k}\right) .
\end{aligned}
$$

The parameters to be calculated by the HB model are the vector of $\boldsymbol{u}_{k}(i)$ for each individual respondent, the vector $\bar{u}$ of means of the distribution of scale positions, and the matrix $\mathbf{V}_{u}$. Rather than trying to integrate across the parameters of interest, the calculation is done using a Markov chain Monte Carlo (MCMC) iterative procedure, which generates draws of all parameters in the joint distribution (Eq. [3]). The priors of $\{\boldsymbol{u}\}_{k}, \overline{\boldsymbol{u}}$, and $\mathbf{V}_{u}$ are then set to be uninformative $(=0)$. According to the Bernstein-von Mises theorem, under unrestrictive conditions, the posterior distribution of a parameter is effectively independent of the prior distribution when the sample of data is sufficiently large (Hipp and Michael, 1976).

\section{Statistical Analysis}

Anchored $\boldsymbol{B} \boldsymbol{W} \boldsymbol{S}$. Data from the anchored BWS were estimated through $\mathrm{HB}$ analysis using $\mathrm{CBCHB}$ v.5.0.4 (www.sawtoothsoftware.com). The MCMC estimation was carried out with 10,000 iterations before the results were used, followed by an additional 10,000 iterations to calculate importance weights for each interviewee. Individual part-worth utilities were then transformed into a common rating scale following the approach in Lagerkvist et al. (2012).

The predictive accuracy of the HB estimation was assessed through the chance ratio measure (average percentage certainty divided by the predictive power of a chance model). The average percentage certainty varies 
Table 2. Descriptive statistics of the study sample $(\mathrm{n}=123)$

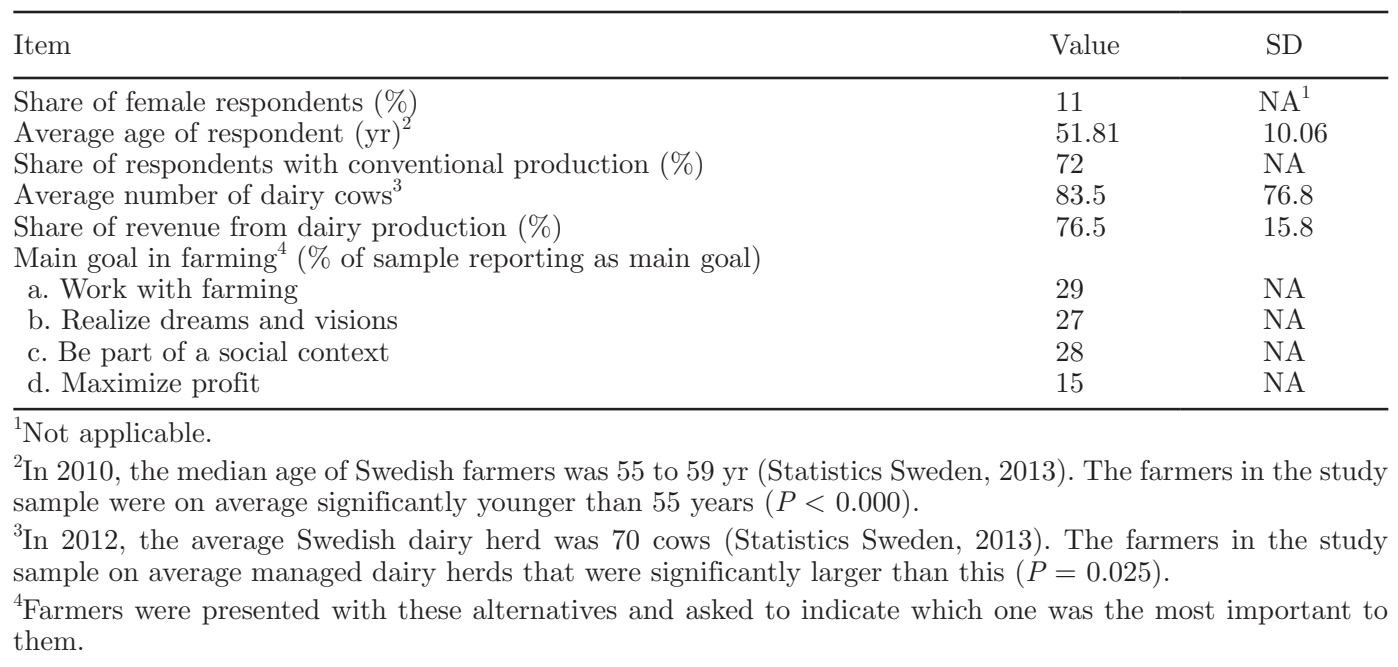

between 0 (the model fits the data at the chance level) and 1 (perfect fit). This was defined by Hauser (1978) as the difference between the estimated log-likelihood of the fitted model and the log-likelihood of the chance model, divided by the negative of the log-likelihood of the chance model. Based on the choice task in Figure 1, a chance model has a predictive power of $1 / 6$ ( 1 out of 6 choice options, i.e., 5 attributes and 1 dual-response alternative).

Principal Component Factor Analysis of Use and Non-Use Values. We performed principal component factor analysis (PCA) of the logit scaled part-worth utilities (taken here as measurement items) obtained from the HB estimation to check the dimensionality of the anchored BWS data. According to recommendations by Hair et al. (2010), we first scrutinized measurement items according to a measure of sampling adequacy and thus according to their suitability for PCA. To this end, we used Kaiser's overall measure of sampling adequacy (KMO). We investigated internal structure by PCA, taking the assumed formative relationship between the attribute and the economic value construct into consideration. We opted for explorative rather than confirmatory PCA due to lack of empirical knowledge about the content and structure of the individual components of the economic value construct. Exploratory PCA allows measurement items to be freely associated with component factors, based on their correlations with these factors.

Before evaluating the principal component factor solution, we rotated it by oblique rotation, which allowed component factors to correlate. The rotation meant that for each component factor, the number of highly loading measurement items was minimized, whereas for the measurement items, their loading on a single component factor was maximized. Based on recommendations made by Hair et al. (2010), we considered measurement items with factor loadings $<0.5$ to be practically insignificant and therefore we deleted these from further analysis. The final principal component factor solution was based only on measurement items with significant factor loadings. We based the number of component factors to retain on the suggestions obtained from the eigenvalues.

\section{RESULTS}

\section{Descriptive Statistics on the Study Sample}

Descriptive statistics on the study sample are presented in Table 2. Compared with the population of Swedish dairy farmers, the sample analyzed here appeared to contain farmers who were significantly younger than the median dairy farmer, and dairy herds significantly larger than the average dairy herd. The farmers appeared to have chosen farming for several reasons, the most important being "work with farming" and the least important "maximize profits."

\section{Attribute Importance}

Table 1 shows the importance of each of the 27 attributes as estimated with the help of the dual-response anchoring approach. With an average percentage certainty of 0.4220 , the chance ratio was 2.53 times better than what a chance model would have predicted. This suggests that model fit and predictive accuracy were adequate.

The results shown in Table 1 provide the empirical representation of the economic value construct associ- 
ated with AWC. The specific AWC attributes of most importance to the participating farmers were satisfaction from knowing that their dairy cows are well-kept (attribute 11); preventing disease, pain, and injury (attribute 18); and possible business development to further improve the way in which dairy cows are kept (attribute 10). Attribute 11 was 68\% more important than attribute 18 (15.14\% divided by $9.02 \%$ ) according to the ratio scale properties.

We found that 4 attributes had importance weights lower than the weight for the anchor threshold. These were attributes 27: To contribute to consumers being offered high-quality food product; 14: To make sure my dairy production is ethical; 5: To make sure that my dairy cows are kept in such a way that my work environment is good; and 7: To make sure that my dairy production is run in such a way that the current animal welfare law is satisfied, but not more. This suggests that farmers associate a negative utility with these attributes.

It is worth noting that 8 of the 10 most important attributes represented non-use values, with 5 of these focusing on the existence values. Only 2 out of the top 10 AWC attributes related to use values. The total share of importance for the top 10 attributes covered as much as $70 \%$ of the ratio scale.

\section{PCA}

The PCA validated the unidimensionality of the AWC economic construct (see Table 3). We removed 2 motivational attributes; that is, measurement items (attributes 3 and 5), from further analysis because they were not significantly associated with any underlying component factor. Following this, we obtained a factor solution containing 4 component factors. Component factor 1 was composed of pure non-use values, existence values, and use values. Component factor 2 was composed of bequest values, option values, and paternalistic altruism. Component factor 3 was composed exclusively of use values. Component factor 4 was composed of use values and one pure non-use value. Together, these 4 component factors explained $88.02 \%$ of the total variance, which is considered acceptable in social sciences (Hair et al., 2010). The overall KMO of the matrix was 0.911, with individual KMO measures ranging between 0.835 and 0.955 , showing that the matrix is suitable for PCA. Looking at the share of total variance explained by the 4 component factors, the results suggest that component factor 1 was the most important, explaining $69.17 \%$ of total variance and thus heavily dominating the component factor structure. The remaining 3 factors each explained between 4.05 and $8.27 \%$ of total variance and therefore constituted only a minor part of the component factor structure. This pattern of eigenvalues clearly confirmed that the economic value construct is unidimensional, as implied by the theoretical understanding of the construct.

\section{DISCUSSION}

Our purpose with this study was to identify empirically the use and non-use values that motivate dairy farmers in work related to the welfare of their dairy cows, and how farmers prioritize between these values. In so doing, we examined the empirical content and structure of the economic value dairy farmers associate with AWC. Use values are economic values in FAW that are derived from productivity considerations. Nonuse values are economic values in FAW derived from the wellbeing of the animals, irrespective of the present or future use the farmer may make of the animal.

\section{Aspects Related to Data and Method Issues}

From a data quality point of view, the response rate obtained here was admittedly considerably lower that what is generally obtained in questionnaire-based studies targeting Swedish dairy farmers. Possible explanations for the low response rate are that (1) some farmers may still not be comfortable with answering internet-based questionnaires due to poor familiarity with computers and information technology; and (2) the questionnaire was considered too extensive and tiresome to complete compared with the reward given. The findings may thus be biased because the dairy farmers responding to the questionnaire may have been those who find questions related to AWC more important. Furthermore, when asking questions related to farmers' views about the wellbeing of the animals, there is a risk of social desirability bias (e.g., Lusk and Norwood, 2010). This means that the responding farmers may have responded in a way that exaggerated attributes they believe are socially desirable. The findings need to be interpreted in light of this. Compared with the general population of Swedish farmers, the farmers included in our sample were significantly younger $(P<$ $0.000)$ and their dairy herds were significantly larger $(P=0.025)$. This means that our findings should be considered more representative of the content and structure of the economic value in AWC perceived by younger farmers who are operating larger dairy farms.

It should also be acknowledged that the data collection procedure ran for a period of 3 mo. This long period could have biased the findings by allowing time for events affecting the respondents' motivation to work with animal wellbeing to occur. However, to the best of our knowledge, nothing extraordinary happened 


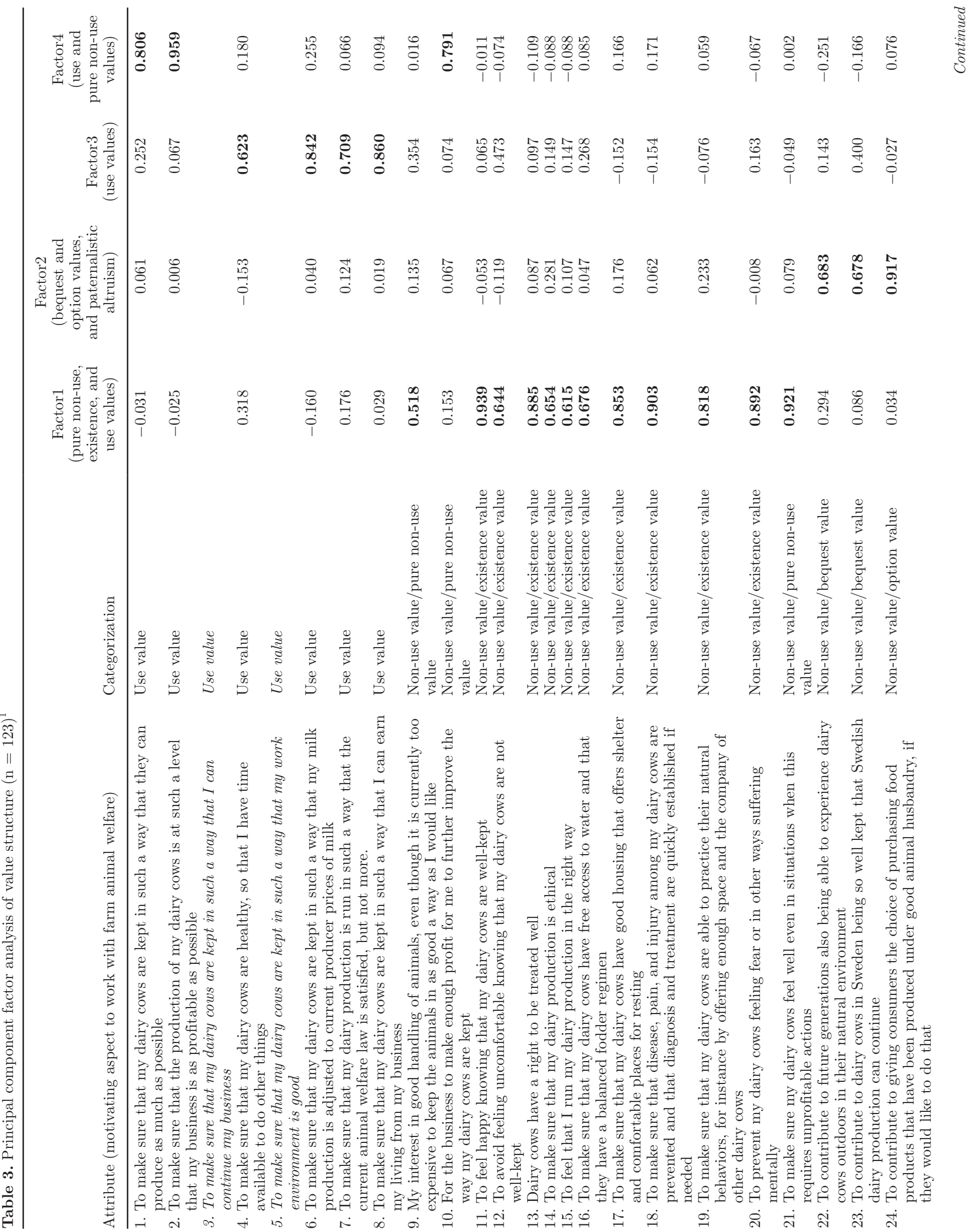


during the study period that could have affected their motivation.

Upon running the PCA, we found that 2 measurement items did not load significantly on any component factor. These were therefore deleted from further analysis, although deleting a measurement item in a formative measurement model may alter the meaning of the construct (e.g., Jarvis et al., 2003). This was not thought to be a problem in our case, because the correlation with the underlying factor was insignificant, having a value $<0.5$. Such a measurement item is practically unrelated with the component factor (Hair et al., 2010).

\section{General Discussion}

Compared with previous literature related to farmers' FAW-related behaviors, this study provides insights into what motivates dairy farmers in their work relating to AWC. This is done in 2 ways: First, the types of use and non-use values dairy farmers perceive as motivating them in their AWC-related work are identified empirically. Second, the way in which dairy farmers prioritize between these motivating factors is identified, acknowledging that some are of use type and others are of non-use type. In this way, this study adds to the existing literature by describing the empirical content and structure of the economic value dairy farmers associate with AWC. Moreover, by basing the study in a BWS framework (Finn and Louviere, 1992; Marley and Louviere, 2005), we were able to achieve this while explicitly considering how dairy farmers make tradeoffs between the different attributes of the economic value construct. The economic value construct used here could be related to the theory of planned behavior (Ajzen 1991, 2002), which has been widely used in examining farmers' attitudes to FAW. Indeed, the economic value construct presented here can be viewed as a motivational construct that affects beliefs, which in turn form the attitude construct (Hansson and Lagerkvist, 2014).

Similar to findings reported by Hansson and Lagerkvist (2015), and in line with the theoretical understanding of the economic value in FAW, our results suggest that the AWC-related work done by dairy farmers is influenced by values of both use and non-use type. With the approach we applied, we were able to investigate in detail how dairy farmers prioritize among different use and non-use values and thus obtain an indication of how these are ranked.

The most important attribute found in this study was "To feel happy knowing that my dairy cows are well-kept." This suggests that the dairy farmers' own wish to know that they are treating their animals appropriately is the main factor motivating their AWC- 
related work. Furthermore, our findings suggest that dairy farmers in their AWC-related work are especially influenced by non-use values. Out of the 10 most important attributes found this this study, 8 were of nonuse type. This suggests that dairy farmers work with AWC mainly for reasons other than those connected to profitability and productivity. In contrast to previous literature describing livestock farmers' views on FAW (e.g., Dockès and Kling-Eveillard, 2006; Hubbard et al., 2006, 2007), our findings appear to indicate greater importance of aspects not related to profitability and productivity. However, because of the significant methodological differences between studies, such comparisons need to be acknowledged as highly speculative.

Out of the 8 non-use values present among the 10 most important attributes of the economic value in AWC, we found that 5 were of an existence value type (To feel happy knowing that my dairy cows are wellkept; Dairy cows have a right to be treated well; To feel that I keep my dairy production in the right way; To make sure that disease, pain, and injury among my dairy cows are prevented and that diagnosis and treatment are quickly established if needed; To make sure that my dairy cows feel well even when this requires unprofitable actions). This suggests that AWC-related work is motivated especially by ideas of absolute rights that the animals are assumed to have and by the feelings of happiness that result from treating animals well. The 2 use values among the 10 most important attributes of the economic value in AWC were both related to the profitability of the business. Taken together, the 10 most important attributes suggest that profitability of the business is important but that the absolute rights the animals are assumed to have and the feelings of happiness associated with treating animals well are equally or even more important.

We found that 4 attributes had lower importance weight than the anchor threshold, suggesting that these attributes are likely to function as inhibitors of AWC work motivation for dairy farmers. These were attributes 27: To contribute to consumers being offered high-quality food products; 14: To make sure my dairy production is ethical; 5: To make sure that my dairy cows are kept in such a way that my work environment is good; and 7: To make sure that my dairy production is run in such a way that the current animal welfare law is satisfied but not more. Thus, working with AWC to improve these attributes would lead to disutility for the dairy farmers studied. Interestingly, 3 of these (attributes 5, 14, and 27) are very similar to aspects of AWC that emerged as important and motivating in an interview study by Hansson and Lagerkvist (2015). The in-depth interview technique used in that study had several important merits in that it allowed the respondents to mention aspects they may not have thought of initially. However, the contradictory findings presented here stress the importance of also considering respondents' tradeoffs. In particular, the construction of the anchored BWS approach we used targeted the respondents to consider their tradeoffs.

The theoretical understanding of economic value in FAW assumes use and non-use values to form a unidimensional construct. Although unidimensionality is required for the appropriateness of using the BWS measurement approach, this central tenet can also be used to test the validity of the theoretical claim. Hence, our PCA of the data allowed us to provide empirical support for the unidimensionality of the construct. Thus, we allowed the data to be freely associated with underlying component factors based on patterns in the data.

The implications of understanding the empirical content and structure of the economic value construct in AWC are both practical and theoretical. The insights we provide into the economic value construct can be used by the agricultural industry when developing policy and advice directed at dairy farmers, because these insights improve our understanding about what motivates dairy farmers to work with AWC. This could be a valuable basis for affecting behavior. For instance, the insights provided here can be used to develop communication about policy and advice to dairy farmers as a way of achieving better acceptance of both private and public AWC standards. Insights provided here can also be used by the dairy industry to communicate to the public what motivates dairy farmers to work with AWC. This is important, especially in light of findings by Te Velde et al. (2002) that livestock farmers feel bad about believing that others think that the wellbeing of the animals is not important to them. In this respect, communicating the importance of existence values as motivating farmers in their work with AWC appears as important. Furthermore, if future research can confirm correlations between dairy farmers' perceived economic value in $\mathrm{AWC}$ and the actual AWC on their farms, insights such as those provided here can be used as a basis for communication with consumers of dairy products. For consumers interested in the origin of the dairy products they purchase and the conditions under which they have been produced, this would be valuable information and serve as a basis for more informed purchases. From a theoretical point of view, insights into the empirical structure of the economic value construct can be used when developing models aimed at predicting dairy farmers' behaviors. This can be done by taking into consideration a broader set of attributes of the economic value construct instead of only profitability and productivity attributes. Developing such models 
would of course also be a way of contributing knowledge for use in developing future agricultural policy.

Previous research has found that farmers' attachment to their animals may depend on the species kept and the purpose of keeping the animal (Bock et al., 2007), which may also influence their FAW-related behaviors. With our application to dairy farmers, the findings presented in this study contribute new knowledge in this regard, especially about the content and structure of the economic value dairy farmers associate with AWC. In future studies, the economic value perceived by farmers keeping other types of animals should be evaluated. This would be beneficial by further confirming the empirical content and structure of the economic value construct associated with FAW and in evaluating whether and how attributes of the economic value construct depend on the type of animal kept. Such studies may benefit from using the approach and set of attributes developed for this particular study. Furthermore, here we evaluated the content and structure of the economic value construct associated with AWC across the study sample. Future studies should analyze the effect of possible individual differences among farmers on the economic value construct identified here to further our understanding of what forms dairy farmers' motivations to work with AWC.

\section{CONCLUSIONS}

Our findings indicate that dairy farmers are influenced by both use and non-use values in their AWCrelated work, and that they are especially influenced by non-use values. The dairy farmers surveyed seemed to be influenced by values associated with ideas of the absolute rights that the dairy cows are assumed to have and by happiness from knowing that the dairy cows are treated well. The most important attribute found this study was "To feel happy knowing that my dairy cows are well-kept."

\section{ACKNOWLEDGMENTS}

This study was funded by the Swedish Research Council Formas (grant no: 2011-254, Stockholm, Sweden), which is gratefully acknowledged. The authors are also grateful to Norm, a marketing research company in Stockholm, Sweden, for assisting in data collection.

\section{REFERENCES}

Ajzen, I. 1991. The theory of planned behavior. Organ. Behav. Hum. Decis. Process. 50:179-211.

Ajzen, I. 2002. Perceived behavioral control, self-efficacy, locus of control, and the theory of planned behavior. J. Appl. Soc. Psy- chol. 32:665-683. http://dx.doi.org/10.1111/j.1559-1816.2002. tb00236.x.

Allenby, G. M. 1997. An Introduction to Hierarchical Bayesian Modeling. Tutorial notes, Advanced Research Techniques Forum. American Marketing Association, Chicago, IL.

Allenby, G. M., and P. Rossi. 2003. Perspectives based on 10 years of HB in marketing research. Sawtooth Software, Sequim, WA.

Bock, B. B., M. Prutzer, F. Kling Eveillard, and A. Dockes. 2007. Farmers' relationship with different animals: The importance of getting close to the animals. Case studies of French, Swedish and Dutch cattle, pig and poultry farmers. Int. J. Sociol. Agric. Food 15:108-125.

Carver, C. S., and T. L. White. 1994. Behavioral inhibition, behavioural activation, and effective responses to impending reward and punishment: The BIS/BAS scales. J. Pers. Soc. Psychol. 67:319 333.

Cross, P., D. Rigby, and G. Edward-Jones. 2012. Eliciting expert opinion on the effectiveness and practicality of interventions in the farm and rural environment to reduce human exposure to Escherichia coli O157. Epidemiol. Infect. 140:643-654. http://dx.doi. org/10.1017/S0950268811001257.

Depue, R. A., and P. F. Collins. 1999. Neurobiology of the structure of personality: dopamine, facilitation of incentive motivation, and extroversion. Behav. Brain Sci. 22:491-517.

Dockès, A. C., and F. Kling-Eveillard. 2006. Farmers' and advisers' representations of animals and animal welfare. Livest. Sci. 103:243-249. http://dx.doi.org/10.1016/j.livsci.2006.05.012.

Erdem, S., D. Rigby, and A. Wossink. 2012. Using best-worst scaling to explore perceptions of relative responsibility for ensuring food safety. Food Policy 37:661-670. http://dx.doi.org/10.1016/j. foodpol.2012.07.010.

Finn, A., and J. J. Louviere. 1992. Determining the appropriate response to evidence of public concern: The case of food safety. J. Publ. Pol. Market. 11:12-25.

Hair, J. F., W. C. Black, B. J. Babin, and R. E. Anderson. 2010. Multivariate Data Analysis-A Global Perspective. 7th ed. Pearson, Upper Saddle River, NJ.

Hansson, H., and C. J. Lagerkvist. 2014. Defining and measuring farmers' attitudes to farm animal welfare. Anim. Welf. 23:47-56. http://dx.doi.org/10.7120/09627286.23.1.047.

Hansson, H., and C. J. Lagerkvist. 2015. Identifying use and nonuse values of animal welfare: Evidence from Swedish dairy agriculture. Food Policy 50:35-42. http://dx.doi.org/10.1016/j. foodpol.2014.10.012.

Hauser, J. R. 1978. Testing and accuracy, usefulness, and significance of probabilistic choice models: An information-theoretic approach. Oper. Res. 26:406-421.

Hipp, C., and R. Michael. 1976. On the Bernstein-von Mises approximation of posterior distribution. Ann. Stat. 4:972-980.

Hubbard, C., M. Bourlakis, and G. Garrod. 2006. Farmers' perceptions of animal welfare across the UK farm assurance schemes, The rural citizen: Governance, culture and wellbeing in the 21st century. University of Plymouth, Plymouth, UK.

Hubbard, C., M. Bourlakis, and G. Garrod. 2007. Pig in the middle: Farmers and the delivery of farm animal welfare standards. Br. Food J. 11:919-930. http://dx.doi.org/10.1108/00070700710835723.

Huber, J., and K. Train. 2001. On the similarity of classical and Bayesian estimates of individual mean partworths. Mark. Lett. 12:259-269.

Ingenbleek, P. T. M., and V. M. Immink. 2011. Consumer decisionmaking for animal-friendly products: Synthesis and implications. Anim. Welf. 20:11-19.

Jarvis, C. B., S. B. Mackenzie, and P. M. Podsakoff. 2003. A critical review of construct indicators and measurement model misspecification in marketing and consumer research. J. Consum. Res. 30:199-218.

Kauppinen, T., A. Vainio, A. Valros, H. Rita, and K. M. Vesala. 2010. Improving animal welfare: qualitative and quantitative methodology in the study of farmers' attitudes. Anim. Welf. 19:523-536.

Kauppinen, T., K. M. Vesala, and A. Valros. 2012. Farmer attitude toward improvement of animal welfare is correlated with piglet 
production parameter. Livest. Sci. 143:142-150. http://dx.doi. org/10.1016/j.livsci.2011.09.011.

Kielland, C., E. Skjerve, O. Osterås, and A. J. Zanella. 2010. Dairy farmer attitudes and empathy toward animals are associated with animal welfare indicators. J. Dairy Sci. 93:2998-3006. http:// dx.doi.org/10.3168/jds.2009-2899.

Kling-Eveillard, F., A. C. Dockès, and C. Souquet. 2007. Attitudes of French pig farmers towards animal welfare. Br. Food J. 11:859869. http://dx.doi.org/10.1108/00070700710835679.

Lagerkvist, C. J. 2013. Consumer preferences for food labelling attributes: Comparing direct ranking and best-worst scaling for measurement of attribute importance, preference intensity and attribute dominance. Food Qual. Prefer. 29:77-88. http://dx.doi. org/10.1016/j.foodqual.2013.02.005.

Lagerkvist, C. J., H. Hansson, S. Hess, and R. Hoffman. 2011. Provision of farm animal welfare: Integrating productivity and non-use values. Appl. Econ. Perspect. Policy 33:484-509. http://dx.doi. org/10.1093/aepp/ppr037.

Lagerkvist, C. J., J. J. Okello, and N. Karanja. 2012. Anchored vs. relative best-worst scaling and latent class vs. hierarchical Bayesian analysis of best-worst choice data: Investigating the importance of food quality attributes in a developing country. Food Qual. Prefer. 25:29-40. http://dx.doi.org/10.1016/j.foodqual.2012.01.002.

Lattery, K. 2011. Anchoring maximum difference scaling against a threshold-Dual response and direct binary responses. Sawtooth Software, Sequim, WA.

Lusk, J. L., and B. C. Briggeman. 2009. Food values. Am. J. Agric. Econ. 91:184-196. http://dx.doi.org/10.1111/j.1467-8276.2008.01175.x.

Lusk, J. L., and F. B. Norwood. 2010. Direct versus indirect questioning: An application to the well-being of farm animals. Soc. Indic. Res. 96:551-565.

Lusk, J. L., F. B. Norwood, and R. W. Pricket. 2007. Consumer preferences for farm animal welfare: Results of a nationwide telephone survey. Working Paper. Department of Agricultural Economics, Oklahoma State University, Stillwater.

Marley, A. A. J., and J. J. Louviere. 2005. Some probabilistic models of best, worst, and best-worst choices. J. Math. Psychol. 49:464480. http://dx.doi.org/10.1016/j.jmp.2005.05.003.

McFadden, D. 1974. Conditional logit analysis of qualitative choice behaviour. Pages 105-142 in Frontiers in Econometrics. P. Zarembka, ed. Academic Press, New York, NY.

McInerney, J. 2004. Animal Welfare, Economics and Policy. Report on a Study Undertaken for the Farm \& Animal Health Economics Division of Defra, Exeter, UK.

Rossi, P., and G. M. Allenby. 1993. A Bayesian approach to estimating household parameters. J. Mark. Res. 30:171-182.

Sándor, Z., and M. Wedel. 2005. Heterogeneous conjoint choice designs. J. Mark. Res. 42:210-218. http://dx.doi.org/10.1509/ jmkr.42.2.210.62285.

Sawtooth Software. 2009. Anchored Scaling in MaxDiff Using Dual Response. Accessed Sep. 15, 2014. http://www.sawtoothsoftware. com/download/techpap/dualresponsemaxdiff.pdf.

Statistics Sweden. 2013. Jordbruksstatistisk Årsbok 2013 (Yearbook of agriculture statistics 2013). Statistics Sweden, Agriculture Statistics Unit, Örebro, Sweden.

Te Velde, H., N. Aarts, and C. van Woerkum. 2002. Dealing with ambivalence: Farmer's and consumer's perceptions of animal welfare in livestock breeding. J. Agric. Environ. Ethics 15:203-219.

Thurstone, L. L. 1927. A law of comparative judgement. Psychol. Rev $34: 273-286$.

Train, K. 2009. Discrete Choice Methods with Simulation 2nd ed. Cambridge University Press, Cambridge, UK.

van Huik, M. M., and B. B. Bock. 2007. Attitudes of Dutch pig farmers towards animal welfare. Br. Food J. 11:879-890. http://dx.doi. org/10.1108/00070700710835697. 